\title{
Nanotechnologies, Risks and Societal Concerns
}

\author{
Sandrine Gaymard ${ }^{1} \&$ Wilson Engelmann ${ }^{2}$ \\ ${ }^{1}$ University of Angers, Department of Psychology, France \\ ${ }^{2}$ University of Vale do Rio dos Sinos, Department of Law. São Leopoldo. Rio Grande do Sul, Brazil \\ Correspondence: Sandrine Gaymard, University of Angers, Laboratoire de Psychologie des Pays de la Loire \\ (LPPL) EA 4638, Maison de la recherche Germain Tillion, 5 bis boulevard Lavoisier 49045 Angers cedex 01, \\ France. Tel: 33-241-226-446. E-mail: Sandrine.gaymard@univ-angers.fr
}

Received: June 25, 2016

Accepted: August 18, 2016

Online Published: August 30, 2016

doi:10.5539/mas.v10n10p241

URL: http://dx.doi.org/10.5539/mas.v10n10p241

\begin{abstract}
The question of nanotechnologies and societal concerns is a subject which has been developing for several years and constitutes an indicator of an evolution in the awareness of nanotechnologies as an inherent risk with social and ethical issues. Two disciplines in human and social sciences, social psychology and law, associate their fields of competence and their view of this new societal phenomenon. First an exploratory study of the social representation of nanotechnologies is conducted with Humanities and Social Sciences (HSS) students vs Exact Science (ES) students. Results highlight differences between these two groups. Then Law and the challenges to appropriate the innovations brought about by nanotechnology is discussed. In the light of these two disciplines the question of knowing if the human and social science are ready to deal with these new challenges is debated.
\end{abstract}

Keywords: ethical issues, exact sciences students, humanities and social sciences students, impact science, nanotechnologies, production science, risks

\section{Introduction}

Nanotechnology is expanding in research laboratories and the results are transferred to industries and generate new products already available on the consumer market. Nanotechnology has tremendous potential to contribute to human flourishing in socially just and environmentally sustainable ways. However, nanotechnology is unlikely to realize its full potential unless its associated social and ethical issues are adequately addressed (Gaymard \& Engelmann, 2015).

The problem to be investigated can be described as follows: under what conditions the ethical, legal and social impacts of nanotechnology should be reconciled and related to studies of the safety and control of the risks of advances in nanoscale? This is crucial in order to ensure the safeguard of living beings' health and the protection of the environment. The development of new technologies can contribute to the improvement of quality of life. The field of nanotechnologies, which is a developing field, is no doubt one of the most promising. However, like all new technologies, there is an inherent risk in nanotechnology with social and ethical issues. These include various causes for concern linked to health, safety, the environment, privacy...

In the last few years an evolution can be seen in research in social sciences in the field of nanotechnologies. Shapira, Yountie and Porter (2010) did research in nanotechnology and social science literature to elaborate a database. They combined articles from the Web of Science's Social Science Citation Index and Arts and Humanities Citation Index and articles from Scopus. They showed an increase in citations of social scientists' works since 2005. The emergence of new fields or new technologies raises questions and believes that are more or less accurate. In 2009, Sandler notes three misconceptions about the social and ethical issues:1. It is too soon to tell what the social and ethical issues are; 2 . The nanotechnology revolution is inevitably good; 3 . The point of the social and ethical issues is to secure public acceptance. If a large number of papers on nanoethics can be found (e.g. Johnson, 2007; Kermish, 2012; Swierstra \& Rip, 2007), approaching this question from the angle of the study of common sense constitutes a more original direction. Certain works deal with the question of risk/benefit perception or that of trust in nanotechnologies ( $\AA$ m, 2011; Gupta, Fischer, \& Frewer, 2015) but it must be acknowledged that there exists little research in the field of psychology.

In the domain of social psychology, the study of social representations constitutes a major advance in understanding social thinking and its practices (Gaymard, 2014; Gaymard \& Tiplica, 2014; Moscovici, 1961/76). 
This reveals interactions between science and common sense in different contexts. The question of distance from the object is important as the representation is the reflection of practices and of the cultural environment (Gaymard, Kay, \& Etoundi, 2015; Gaymard, Tiplica, Koh, \& Wong, 2015). The structural approach defends the existence of a central core representing the collective part of the representation, and a periphery that would appear to be linked more with individual practices. Although interesting to describe the configuration of the social representation, this model nevertheless has limits when the normative aspects of the representation are addressed (Gaymard, 2014). At the moment we can ask ourselves how nanotechnology is integrated into common sense (to what degree? in which particular domain or context?) since it is a new field certainly, but it is no longer unknown in developing countries. Also how are the advantages and risks integrated into this representation? Does this representation illustrate certain trust? Evoking the idea of risk effectively makes it possible to apprehend to what extent nanotechnologies are perceived. The question of distance from the object is to be asked if interviewing in fields of training in relation with the application of nanomedicines or not. For example, use of the term "nanotechnologies" is not common in the field of Humanities and Social Sciences (HSS) whereas it is quite usual and necessary in the field of Exact Sciences (ES) (Medicine, biology ...).

The social representation of new technologies, specifically nanotechnology, is a new field for the construction of legal expertise knowing that the conditionality theory has revealed that social norms could cause legal norms to evolve (Gaymard, 2014). For a long time the law has constituted an area of knowledge in which theory and practice are separated, thus presenting difficulties in its approach to them. However, as a result of the techno-scientific developments lately produced by human activities, several movements of transformation of the law have been set in motion. One of them, which will be the object of study in this text, refers to the social perception of the impacts - positive and negative - that will be generated from the ability to access the nanoscale. This opens up the possibility of structuring one transdisciplinary field of knowledge where social psychology and law together present certain perspectives, as will be seen below. Here the authors propose a dual approach with first of all an exploratory study of the social representation of nanotechnologies among Exact Science (ES) students and Humanity and Social Sciences (HSS).students.

\section{Method}

\subsection{Population}

A group of $20 \mathrm{HSS}$ students (average age 21.7 and $\mathrm{SD}=2.81$ ) and a group of $18 \mathrm{ES}$ students (average age 22.8 and $\mathrm{SD}=2.90$ ) took part in the study. Among the HSS students, 17 students were doing linguistic and foreign language studies and 3 students were doing psychology. Among the ES students 4 were doing medical studies, 2 mathematics, 1 radiography, 5 physics, 4 pharmaceutical, 1 biophysics and 1 chemistry.

\subsection{Tools}

Two classical complementary tools in the study of social representations were used. Firstly a free associations test, which calls upon spontaneous representation starting from an inductor. The instruction was: "when you hear nanotechnologies, what are the 5 words or expression that comes to mind?". The second tool is a characterization questionnaire, which as its name indicates seeks to highlight what is more or less characteristic of the object. Its particularity comes from the principle of "block choices" since the respondents must select items from a list according to a precise order. In this study we drew up a list of 9 items based on an exploratory study (Table 1), the procedure to follow being to choose first the 3 items most characteristic of the object by scoring +1 , and second the 3 items least characteristic of the object by scoring -1 ; the remaining items are scored " 0 ".

The association of these two tools is frequent in the structural approach of social representations (for example Gaymard \& Joly, 2013).

Table 1. Items of the characterization questionnaire

\begin{tabular}{ll}
\hline Safety & Useful \\
\hline Risk & Fear \\
\hline Health & Unknown \\
\hline Progress & Useless \\
\hline Danger & \\
\hline
\end{tabular}

\section{Results}

\subsection{Free Associations}

The free associations were analysed through the Evoc program (Vergés, 2005). The 20 HSS students produced 
100 associations (i.e. exactly 5 per person), of which 56 words were different (i.e. a diversity index of .56). In the analysis we retained the words cited at least twice $(10 \%)$ and as the highest frequency the words cited at least five times $(25 \%)$. The words quoted in the first ranks correspond to the ranks equal to or below 2.5 , and those quoted in the last ranks to the ranks above 2.5. Gaymard and Bordarie (2015) explained in more detail how these criteria can be established.

From these criteria the delimitation of the central core and of the periphery (Table 2) shows that for the HSS students, it is the words "sciences" and "technology" that serve as the central words (the most frequent and in the first ranks). As for the first periphery it is highly represented by signifiers directed toward the future (progress, futuristic, modernity) and referring to the scale of the nanometer (small).

Table 2. Social representation of the nanotechnologies among Humanities and Social Sciences students

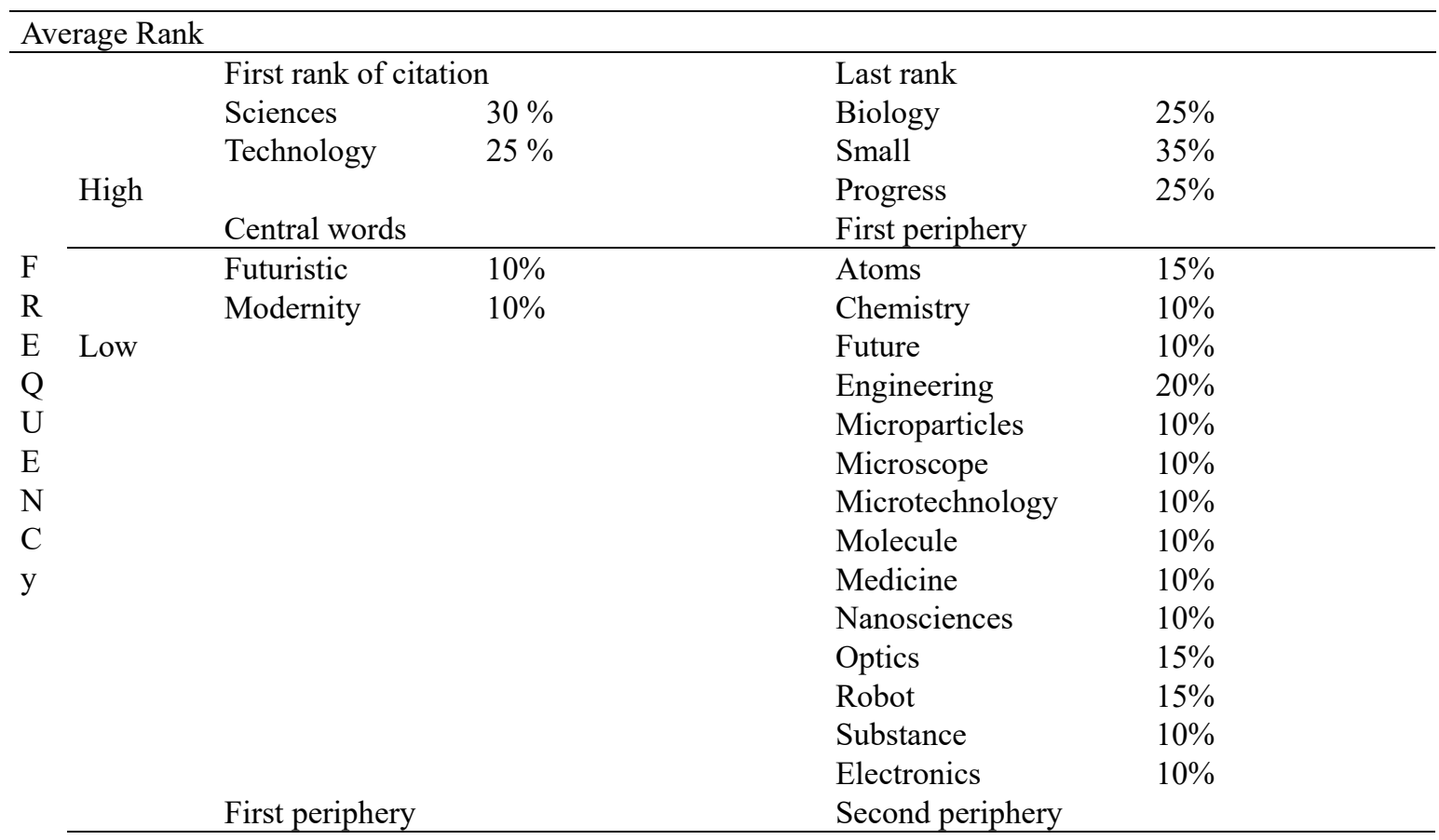

Concerning the ES students (Table 3), on the whole they give slightly fewer associations ( $\mathrm{N}=93$ ) and different words $(\mathrm{N}=49)$, that is, a lesser diversity index (.52). The central core is composed of the item "development ". The periphery is greatly represented by, on one hand, items referring to the scale of nanometer (Atoms, micro-robots, microscope), on the other hand, medicine, chemistry, the notion of substance and technology, the latter belonging to the core of HSS students.

Table 3. Social representation of the nanotechnologies among Exact Sciences students

\begin{tabular}{|c|c|c|c|c|c|}
\hline \multicolumn{6}{|c|}{ Average Rank } \\
\hline & \multirow{6}{*}{ High } & \multicolumn{2}{|c|}{ First rank of citation } & \multicolumn{2}{|l|}{ Last rank } \\
\hline & & Development & $33 \%$ & Atoms & $25 \%$ \\
\hline $\mathrm{F}$ & & & & Micro-robots & $35 \%$ \\
\hline $\mathrm{R}$ & & & & Microscope & $25 \%$ \\
\hline $\mathrm{E}$ & & & & Medicine & \\
\hline Q & & Central words & & First periphery & \\
\hline $\mathrm{U}$ & & Chemistry & $22 \%$ & Future & $11 \%$ \\
\hline $\mathrm{E}$ & & Substance & $22 \%$ & Molecules & $16 \%$ \\
\hline $\mathrm{N}$ & & Technology & $22 \%$ & Robot & $22 \%$ \\
\hline $\mathrm{C}$ & Low & & & & \\
\hline $\mathrm{y}$ & & First periphery & & Second periph & \\
\hline
\end{tabular}




\subsection{The Characterization Questionnaire}

The analysis of the characterization questionnaire shows that for the whole population, useful and progress are the most characteristic of nanotechnologies $(82 \%$ and $79 \%)$ while useless is the less characteristic (76\%) (Tables $4 \& 5)$.

Table 4. Items chosen as being the most characteristic of nanotechnologies for both groups ( $\mathrm{N}=38)$

\begin{tabular}{lc}
\hline Useful & $82 \%$ of the population \\
Progress & $79 \%$ \\
Heath & $63 \%$ \\
Risk & $37 \%$ \\
Safety & $24 \%$ \\
Fear & $8 \%$ \\
Unknown & $5 \%$ \\
Danger & $3 \%$ \\
\hline
\end{tabular}

Table 5. Items chosen as being the least characteristic of nanotechnologies for both groups $(\mathrm{N}=38)$

\begin{tabular}{lc}
\hline Useless & $76 \%$ of the population \\
Fear & $55 \%$ \\
Unknown & $53 \%$ \\
Danger & $50 \%$ \\
Risk & $29 \%$ \\
Safety & $24 \%$ \\
Health & $11 \%$ \\
Useful & $3 \%$ \\
\hline
\end{tabular}

In comparison with ES students, HSS students consider that safety is characteristic of nanotechnologies and the difference is very significant in that no ES student chooses safety as being characteristic of nanotechnologies (khi2=10.84; $\mathrm{p}<$.004). HSS students are also more numerous in considering that risk is characteristic of nanotechnologies $(\mathrm{Khi} 2=12.20 ; \mathrm{p}<.002)$. In contrast health is more characteristic of nanotechnologies for ES students $(\mathrm{Khi} 2=7.82 ; \mathrm{p}<.02)$. As for the item danger, significantly, it is chosen in majority as being non characteristic of nanotechnologies by HSS students whereas ES students do not choose it either as characteristic or non-characteristic of nanotechnologies $(\mathrm{Khi} 2=17.84 ; \mathrm{p}<.000)$ (Table 6$)$. The illustrations of these differences appear in Figures 1 and 2. It is thus possible to visualise what is the most and the least characteristic of nanotechnologies for each group by means of these Kendall diagrams.

Table 6. Significant results (Chi-square test of independence)

\begin{tabular}{|c|c|}
\hline $\begin{array}{l}\text { Safety } \quad X^{2} \quad(2, N=38)= \\
10.84, p<.004\end{array}$ & More characteristic for HSS students. \\
\hline $\begin{array}{l}\text { Risk } \mathrm{X}^{2} \quad(2, \mathrm{~N}=38)= \\
12.20, \mathrm{p}<.002\end{array}$ & More characteristic for HSS students. \\
\hline $\begin{array}{l}\text { Danger } \quad \mathrm{X}^{2} \quad(2, \mathrm{~N}=38) \\
=17.84, \mathrm{p}<.000\end{array}$ & $\begin{array}{l}\text { Less characteristic for HSS students (ES students do not choose it } \\
\text { either as characteristic or non-characteristic of nanotechnologies) }\end{array}$ \\
\hline $\begin{array}{l}\text { Health } \quad \mathrm{X}^{2} \quad(2, \mathrm{~N}=38)= \\
7.82, \mathrm{p}<.02\end{array}$ & More characteristic for ES students. \\
\hline
\end{tabular}




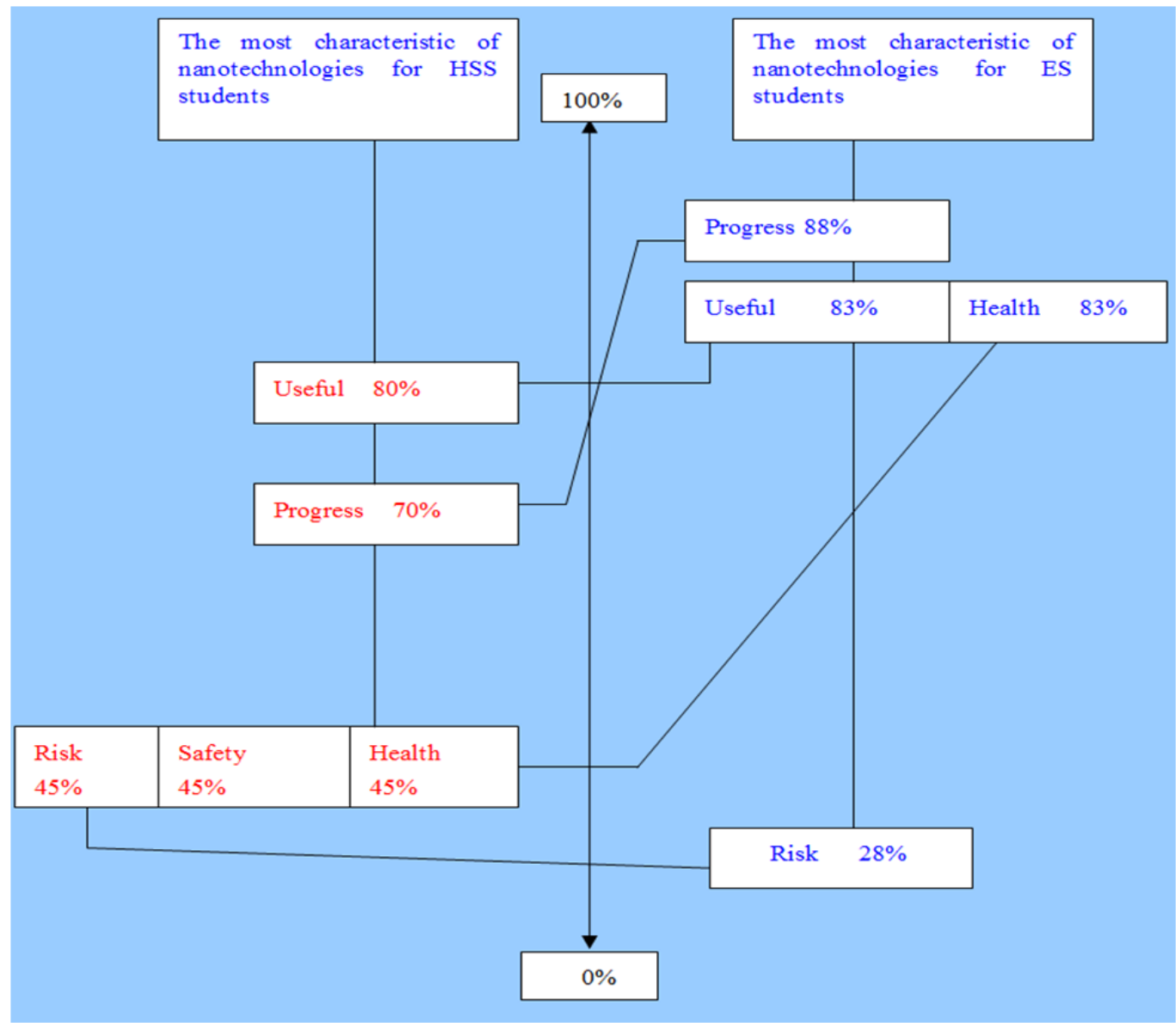

Figure 1. The most characteristic of nanotechnologies for each group (Kendall diagram)

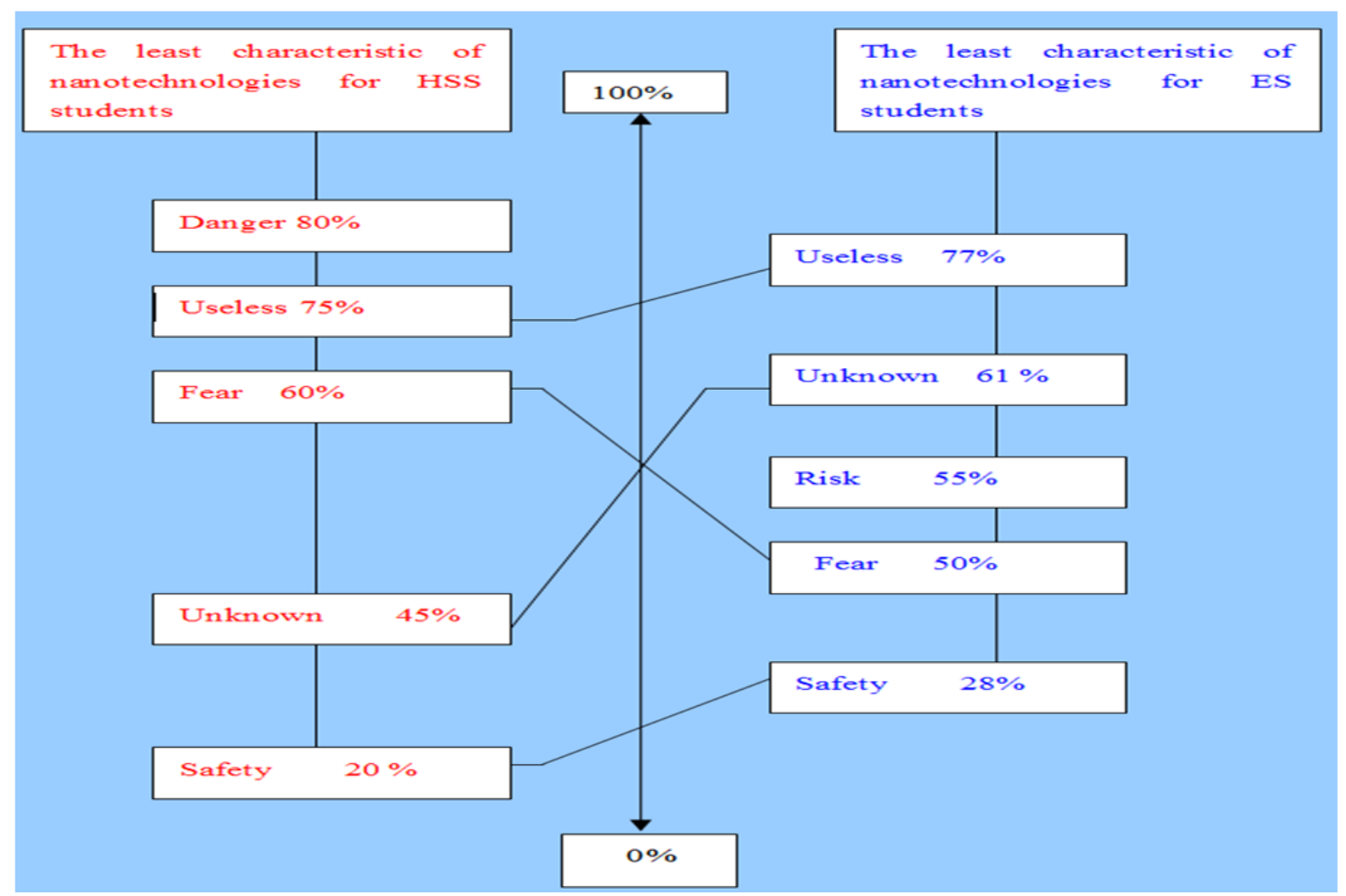

Figure 2. The least characteristic of nanotechnologies for each group (Kendall diagram) 


\section{Law and the Challenges to Appropriate the Innovations Brought by Nanotechnologies}

Beside the traditional division of the various areas of knowledge - Exact Sciences and Humanities and Social Sciences, an opening to another classification exists, which is shown to be best suited for the techno-scientific scenario, in which nanotechnologies can be found; one of the appropriate distinctions is made in relation to the ability of modern science to produce capital and understand the impacts of externalities linked to the production of capital.

Thus Schnaiberg (1997) offers a useful distinction between production science and impact science. As a former chemical engineer in the Canadian aerospace industry, he was perfectly placed to assess the role of institutional agendas in scientific research training. The Sciences of production lead to an increase in production, distribution and consumption of goods and services (including military). Regardless of the levels at which they are applied, the Sciences of production aim to generate results that can come in the form of new consumer goods, new weapons systems, new production processes or new materials. There is a perfect harmony between this categorization of Sciences of production and the nanotechnology revolution. In other words, modern science, unlike the classical notion of science, is not content to observe and describe nature but needs to interact, producing something; that is, techno-scientific knowledge should generate an innovative product. Already Sciences of impact seek to understand the impacts of production lines and the interrelationships established between the natural system and the social one, expanding our understanding of the impacts of production processes and their externalities on the environment and human health (Gould, 2015).

Under the title "Sciences of impact" social psychology and law are to be found. Therefore, the role of these two areas of knowledge is to reflect on the challenges and impacts that may be generated by nanotechnologies in the social, human, legal, political, and economic fields.

By comparing these two areas, it can be understood why the Sciences of production are attracting greater attention and investment for authorities in modern societies. While investment in Sciences of production enables large financial gains, the Sciences of impact enable social questioning of innovation in production. There is virtually no incentive and the opportunity to prevent serious issues of legal nature (liabilities), so that companies that fund studies may denounce the impacts they generate. Moreover, when conducting studies on the impacts of Sciences of production, companies have a great tendency to conclude that there is an absence of negative impacts on the environment and public health. There is almost complete silence on the Sciences of impact, including Law and Social Psychology. In these disciplines, little is being produced on the impacts - positive or negative - of nanotechnologies.

A category of analysis that should be considered is 'risk', present in the panorama provided by the possibilities that are opened up for access to the nanoscale. The perception of risk has several theoretical approaches such as those of Beck (1992) or Douglas and Wildavsky (1982).

Hence Douglas and Wildavsky (1982) mention that risk is a social process, which is why it is considered that such aspects cannot be ignored. Failing this, the focus may be directed to the wrong problems and the judgment of what dangers are really to be feared may be affected.

The idea of public perception of acceptable risk levels comes from collective constructions, namely that the decision-making or selection of dangers and the choice of the social fabric go together, reflecting contemporary reality. This indicates that any discussion about the risk must be preceded by a consensus on what approach and threat should be considered. The most important choice is not made directly, but according to the favored social institutions, a fact that complicates the attempt to compare ethical systems or even blocks the debate on the perception of risks (Douglas \& Wildavsky, 1982). Horizontalizing the issues presented shows the importance of risk perception of nanotechnologies, which can be observed at the intersection of three levels, as can be seen in Figure 3. 


\section{Risk perceptions}

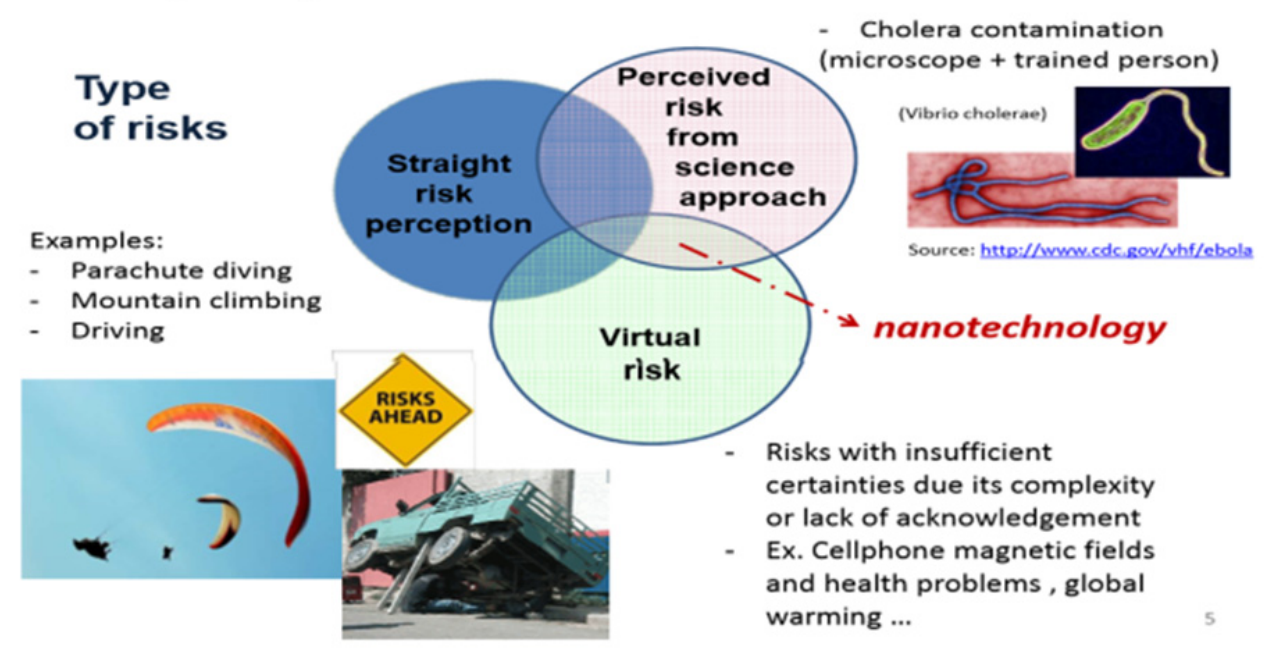

Figure 3. Source: Lenz e Silva, and Hurt (2014)

If the risk perception of situations directly presented can be limited, a first level of risk is, for example, parachute diving, mountain climbing, the mobility of pedestrians and drivers in traffic, among others. A second approach to risk is that perceived by science and the scientist, associating specialized equipment and trained personnel; a third approach relates to risk with insufficient certainty due to their complexity or lack of recognition; this is the case of magnetic fields of mobile phones and health problems, global warming, among others. According to Figure 3, nanotechnology and its risks are in the interconnection of the three levels of risk, bringing a little of each of the fields, hence the high level of complexity to deal with the risks generated from the nanoscale.

Risk is not a category well known to law, and is a theme that is gaining ground in management studies and that needs to be considered and understood by law. To judge the extent of the risk, one should see the broad spectrum within which to present the definitions: "[...] some focus primarily on the probability of occurrence of negative events; others consider the consequences of these events, while there are those that consider both the side of losses and the side of distribution of earnings"(our translation, Damodaran, 2009, p. 27). These risks define elements that emerge through certain words: probability, negative events, consequences, losses and gains. In the case of nanotechnologies, these expressions should guide the construction of a specific regulating framework, as well as that of models for risk management. This will need to operate taking into account these probabilities of damage, from the identification and assessment of risks, which belong to the possible negative events, given the widespread ignorance of the effects that nanoparticles may generate. By measuring these aspects it should be possible to anticipate the variability and complexity of the consequences of the decisions that will be taken with respect to losses and gains. Economic elements then come into play, but also human, social, legal and environmental ones. In other words: the scenario is highly sophisticated, demanding legal responses on the same level.

On the other hand, the number of studies that have been published on the topic of nanosafety speaks for itself. We have seen an almost exponential rise over the past 15 years or so in the number of articles on nanotoxicology. Although only a couple of hundred papers had appeared on the topic of "Nanomaterials: environmental and health effects" before 2000, this number has exploded to over 10000 since 2001. Most of these studies, however, do not offer any kind of clear statement on the safety of nanomaterials. On the contrary, most of them are either self-contradictory or arrive at completely erroneous conclusions (Krug, 2014).

During and after the public hearing held on June 25, 2015, in a joint activity of the Environmental Commission and Sustainable Development and the Committee on Science and Technology, Communication and Information, of the Brazilian House of Deputies some manifestations appear strange especially the manifesto drawn up by the Study Group on Nanoscience and Nanoengineering of the Brazilian Academy of Sciences, criticizing the bills mentioned (Engelmann, 2015). The scientists who signed the manifesto want to imply that nanomaterials do not provide anything new because they already exist in nature ("...nanomaterials are not a recent invention of man and have always existed in nature"). While several countries are seeking to regulate nanomaterials engineered to 
express new and different properties of the same materials at a larger scale, the manifesto aims to convince parliamentarians and Brazilian society that there is nothing new in this technology. However, many nanomaterials are recognized as new chemicals by EPA-TSCA United States since 2010 and the EU REACH China, among others.

\section{Discussion: Are the social sciences prepared to deal with the issues/challenges brought about by the nanoscale?}

The question of nanotechnologies and societal concerns is a subject that is developing in the field of social and ethical issues testifying to an evolution in risk awareness and a revelation of the sciences of impact. If the question of risk perception concerning nanotechnologies is not new (e.g. Fuchs \& Gazsó, 2015), the question of social representations is approached relatively little since it is truth that this field of French origin (Moscovici, 1961/76) and developed in Europe is less known in United States.

The originality of this field of study is to go beyond the level of intra-individual analysis, characteristic of the field of risk perception, and to study lay thinking about risk (Gaymard, 2012; Joffe, 2003). An object of social representation is constructed within communication network and constitutes an invaluable indicator in changes of mentalities (Gaymard et al., 2015). For example nanotechnologies have become an object of social representation because common sense has appropriated this new object the stakes of which have become perceptible to the population. But above all social representations applied to the field of risk can disclose specific believes that can serve as protection for the group and defence of its identity (Gaymard et al., 2015).

First an exploratory study confirms that nanotechnologies are an object of social representations. The free associations technique shows that this object is structured differently according to whether students are registered in HSS or ES. This means that students in these two fields have not elaborated the same social representation of nanotechnologies because they do not have the same practical knowledge linked to their training. The social representation of ES students is more homogeneous and concrete, which illustrates the fact that ES students have a better knowledge of the object due to their practices. It can also be seen that these spontaneous associations do not make any reference to the notion of risk. The object "nanotechnologies" is rather associated to evolution but nobody takes a stand: it is a descriptive social representation. How can these results be interpreted? The contents of the social representation can reflect a certain confidence conveyed by the media. In the latter the question of nanotechnologies is effectively associated to progress, which could explain the content of the social representations. Another but not incompatible explanation might be that nanotechnologies constitute a sensitive topic (or a normative object) and people do not say all they think. A means of verifying this interpretation is to propose a second tool that includes other dimensions of the object, in this case the characterization questionnaire (Gaymard \& Joly, 2013).

The use of this another tool reveals differences concerning these two populations in the perception of the relations between nanotechnologies, danger and risk. No ES student chooses safety as characteristic of nanotechnologies against $45 \%$ of HSS students. Only $16 \%$ of ES students choose danger as "not characteristic" of nanotechnologies against $80 \%$ of HSS students. Through these items we thus observe greater confidence of the HSS students towards nanotechnologies. The concept of risk appears more heterogeneous for ES students since $28 \%$ choose it as the most characteristic while $55 \%$ as the least characteristic. This may be explained by the fact that the ES students come from different fields of study. Finally it is possible to imagine that a public that knows less (in practice) the object studied mainly refers to what is broadcast in the media, that is the benefits of nanotechnologies. It would thus be relevant when training students in particular HSS students, to approach these aspects and to train them to develop their ideas on this subject.

In the age of nanotechnology, people live with the designs of techno features. Unlike the classical conception of science, which merely observes and describes nature; techno-science is at another stage and wants to transform knowledge into a product that can be sold to the consumer. In the anthropocentric age, the human being intends to reproduce all that technology will allow. Nanoscale in various sectors is spread by a number of different technologies thus generating nanotechnology. From then on, it has the potential to produce objects with very different characteristics from those submitted by their counterparts in the developed macro scale.

Human beings are living in a moment when they realize that they are the center of everything, leading to an extreme limit that they have themselves developed, that is everything technology makes it possible to produce and consume. How will future generations be? Will we be producing new diseases despite advances promised by 
nanotechnology applied to medicine? Although there are no conclusive studies on the various stages of the life cycle of nano-objects, which are being produced in increasing quantities and which are reaching the consumer market, advertised as innovative; there is still no specific regulation.

This scenario needs to be examined critically. This is the challenge that we have in this early twenty-first century. Man will need to learn to deal with different forms of regulation, not attached to state Legislature but more produced by different global regulatory actors. It will be necessary to build legal responses by using methodologies such as decision tree and frameworks.

Nanotechnology can contribute to the development of "green" strategies and "environment friendly", helping to reduce the global production of industrial and domestic waste. However, it will also generate the "invisible waste" we do not know how to deal with (Gaymard \& Engelmann, 2015). It will be necessary to inform the public about nanotechnology, its benefits and its risks. It will be necessary to promote public commitment, seeking to guide consumer products from nanotechnology towards the correct disposal of nanotechnological waste. Such are the interdisciplinary challenges, or perhaps transdisciplinary, that should lead Law and Social Psychology to deal with the social, legal, political and environmental impacts on the world at the nanoscale.

To deal with all these new issues, Social Psychology and Law, in addition to other areas of knowledge that have some relation to nanotechnologies, should learn to generate knowledge through interdisciplinarity. This is the suggestion that is a particular matter of the cover of the journal "Nature" (Figure 4).

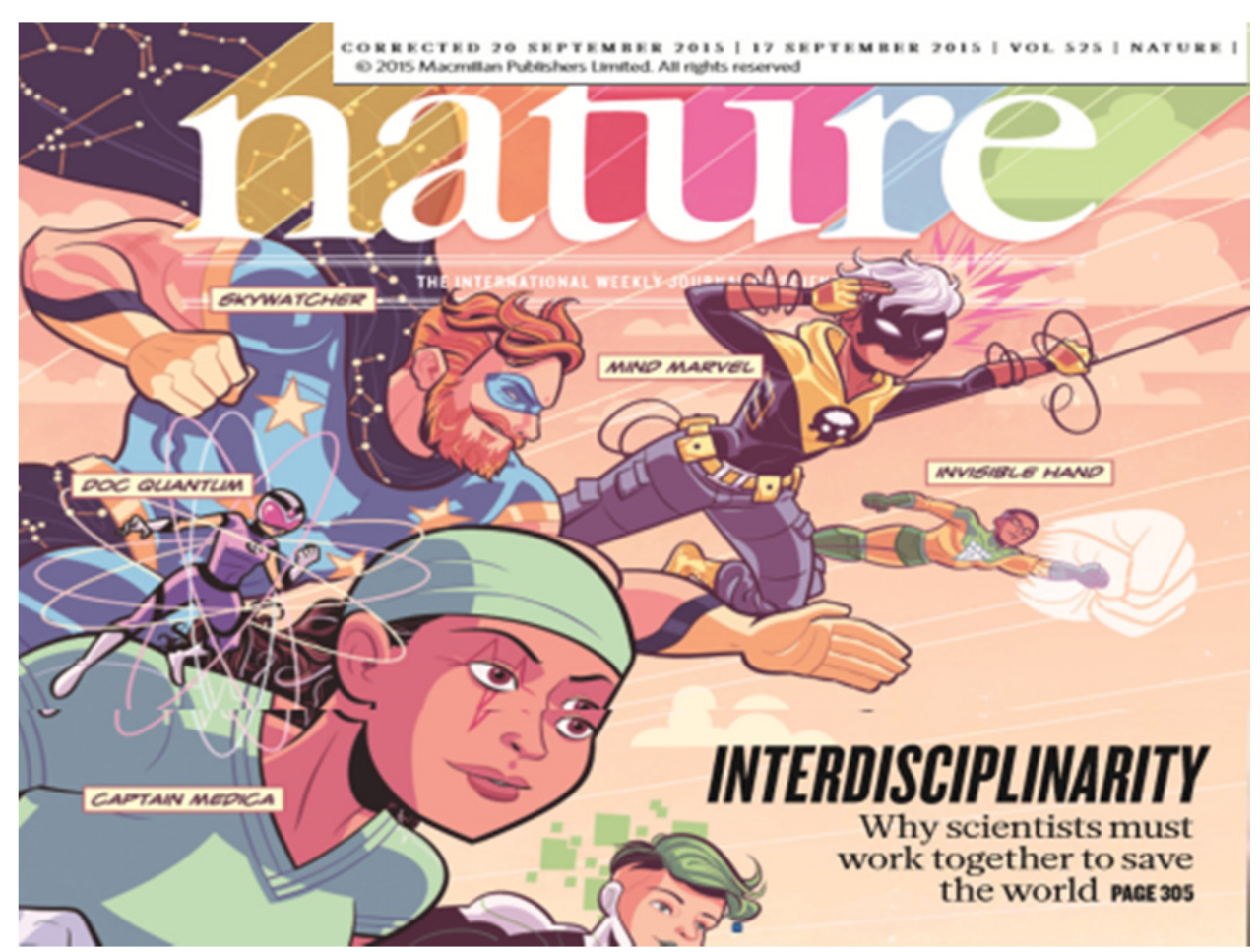

Figure 4. Cover of the journal Nature: http://www.nature.com/news/interdisciplinarity-1.18295

Conflict of interest: "The authors declare that they have no conflict of interest".

\section{References}

$\AA ̊ . m$, T. G. (2011). Trust in Nanotechnology? On Trust as Analytical Tool in Social Research on Emerging Technologies. Nanoethics, 5(1), 15-28. http://dx.doi.org/10.1007/s11569-010-0105-8

Beck, U. (1992). The Risk Society: Towards a New Modernity. Londres: Sage publications Ltd.

Damodaran, A. (2009). Gestão Estratégica do Risco: Uma referência para a tomada de riscos empresariais. Tradução de Félix Nonnenmacher. Porto Alegre: Bookman. 
Douglas, M., \& Wildavsky, A. (1982). Risk and Culture: An Essay on the Selection of Technical and Environmental Dangers. Berkeley, CA: University of California Press.

Engelmann, W. (2015). Primeras tentativas de reglamentación de las nanotecnologías en Brasil. In G. Foladori et al. (Coords.), Nanotecnologías en América Latina: Trabajo y regulación (pp. 41-56). México: Universidad Autonoma de Zacatecas.

Fuchs, D., \& Gazsó, A. (2015). Why the public perception of risks is to be taken seriously: The special case of nanotechnology. NanTrust-dossier, 42. Retrieved from http://epub.oeaw.ac.at/ita/nanotrust-dossiers/ dossier042en.pdf

Gaymard, S. (2012). Pedestrian representation through the analysis of little stories. Psychology of Language and Communication, 16(3), 185-200. http://dx.doi.org/10.2478/v10057-012-0013-9

Gaymard, S. (2014). The theory of conditionality: an illustration of the place of norms in the field of social thinking. Journal for the Theory of Social Behaviour, 44(2), 229-247. http://dx.doi.org/10.1111/jtsb.12039

Gaymard, S., \& Bordarie, J. (2015). The perception of the ideal neighborhood: A preamble to implementation of a "street use code". Social Indicators Research, 120(3), 801-816. http://dx.doi.org/10.1007/s11205-014-0610-1

Gaymard, S., \& Engelmann, W. (2015). Societal and human aspects, nanomedicine and law: Challenges to the appropriate treatment of nanowaste. Oral communication in the 4th NanoFar Autumn School, Nantes, France.

Gaymard, S., \& Joly, P. (2013). La représentation sociale du football chez des jeunes adultes issus d'un milieu social défavorisé. Loisir et Sociétél Society and Leisure, 35(2), 263-292. http://dx.doi.org/10.1080/07053436.2012.10707844

Gaymard, S., \& Tiplica, T. (2014). Conditional respect towards the pedestrian: Differences between men and women and risk modeling by the Bayesian approach. Quality \& Quantity, 48(1), 91-110. http://dx.doi.org/10.1007/s11135-012-9751-y

Gaymard, S., Kay, N., \& Etoundi, J. C. (2015). Climate change and beliefs in Cameroon: A qualitative study among farmers in the Equatorial and Sudano-Sahelian zones. Canadian Social Science, 11(7), 53-64. http://dx.doi.org/10.3968/7273

Gaymard, S., Tiplica, T., Koh, P.P. \& Wong, Y.D. (2015). The social representation of the pedestrian in French and Asian cultures. Journal of Safety Health and Environmental Research, 11(2), 261-273.

Gould, K. A. (2015) Slowing the nanotechnology treadmill: impact science versus production science for sustainable technological development. Environmental Sociology, 1(3), 143-151. http://dx.doi.org/10.1080/23251042.2015.1041211

Gupta, N., Fischer, A. R. H., \& Frewer, L. J. (2015). Ethics, risk and benefits associated with different applications of nanotechnology: A comparison of expert and consumer perceptions of drivers of societal acceptance. Nanoethics, 9(2), 93-108. http://dx.doi.org/10.1007/s11569-015-0222-5

Joffe, H. (2003). Risk: from perception to social representation. British Journal of Social Psychology, 42, 55-73. http://dx.doi.org/10.1348/014466603763276126

Johnson, D. (2007) Ethics and technology 'in the making': an essay on the challenge of nanoethics. Nanoethics, 1(1), 21-30. http://dx.doi.org/10.1007/s11569-007-0006-7

Kermisch, C. (2012). Do new Ethical Issues Arise at Each Stage of Nanotechnological Development? Nanoethics, 6(1), 29-37. http://dx.doi.org/10.1007/s11569-011-0137-8

Krug, H. F. (2014). Nanosafety research - Are we on the right track? Angewandte Chemie International Edition, 53(46), 12304-12319. http://dx.doi.org/10.1002/anie.201403367.

Lenz e Silva, G. F. B., \& Hurt, R. (2014). Risk assessment of nanocarbons: use of analytical hierarchy and control banding approaches for safety management. Oral communication. The Fourth International Conference NANOSAFE 2014, MINATEC, Grenoble, France.

Moscovici, S. (1961/76). La psychanalyse, son image et son public (2nd ed.). Paris: Presses Universitaires de France.

Sandler, R. (2009). Nanotechnology: The social and ethical issues. PEN 16. Retrieved from http://www.nanotechproject.org/publications/archive/pen16/ 
Schnaiberg, A. (1997). Sustainable Development and the Treadmill of Production. In S.Baker et al. (Eds.), The Politics of Sustainable Development: Theory, Policy and Practice within the European Union (pp. 72-88). London \& New York: Routledge Press.

Shapira, P., Youtie, J., \& Porter, A. L. (2010). The emergence of social science research on nanotechnology. Scientometrics, 85(2), 595-611. http://dx.doi.org/10.1007/s11192-010-0204-x

Swierstra, T., \& Rip, A. (2007). Nano-ethics as NEST-ethics: Patterns of Moral Argumentation About New and Emerging Science and Technology. Nanoethics, 1(1), 3-20. http://dx.doi.org/10.1007/s11569-007-0005-8

Vergès, P. (2005). Programme d'analyse des évocations "Evoc". Version non commercialisée. Aix-en-Provence: LAMES-CNRS.

\section{Copyrights}

Copyright for this article is retained by the author(s), with first publication rights granted to the journal.

This is an open-access article distributed under the terms and conditions of the Creative Commons Attribution license (http://creativecommons.org/licenses/by/4.0/). 